\title{
The serum vancomycin assay: A test of historic interest
}

$\mathrm{V}$ ANCOMYCIN IS A GLYCOPEPTIDE ANTIBIOTIC THAT HAS BEEN in clinical use for approximately 35 years. Use of vancomycin has increased significantly over the past decade (1) largely because of the increased prevalence of infections due to coagulase-negative staphylococci, often related to intravascular and other prosthetic devices. In some locales, the emergence of methicillin-resistant Staphylococcus aureus (MRSA) has been a major factor contributing to increased vancomycin use.

It has become standard practice to monitor serum vancomycin concentrations routinely in patients receiving vancomycin (1-3 ). Sensitive, accurate and easy to perform assays are readily available, particularly the fluorescence polarized immunoassay. In the past several years, the conventional wisdom of routine monitoring of serum vancomycin concentrations has been challenged (4-7). It is particularly timely in light of diminishing heath care resources in conjunction with the growth of evidence-based medicine that vancomycin serum monitoring be reassessed.

\section{RATIONALE FOR THERAPEUTIC DRUG MONITORING}

Recently, Cantú et al (6) reiterated the principles underlying therapeutic drug monitoring (TDM):

- There must be a reliable assay available.

- $\quad$ There must be a correlation between the serum drug concentration and clinical efficacy and/or drug toxicity.

- If a correlation between serum drug concentrations and either efficacy or toxicity is known, there must be significant interpatient variability in drug pharmacokinetics, such that predictable serum concentrations cannot be achieved with empirical or weight-based dosing regimens.

\section{TDM AND AMINOGLYCOSIDES}

With eight-hourly dosing of most aminoglycosides such as gentamicin, all of the underlying principles of TDM are present and, therefore, routine monitoring is logical using this dosing regimen. However, with once-daily aminoglycoside dosing, it can be strongly argued that empirical weight-based dosing regimens will consistently result in both therapeutic peak concentrations that take advantage of the drug's concentration-dependent killing, as well as low trough concentrations to minimize toxicity so that routine TDM is unnecessary (8).

\section{TDM AND VANCOMYCIN}

As far as vancomycin is concerned, there is no doubt that there is a reliable and easy to perform serum drug assay. However, there is little, if any, evidence to support a correlation between any particular serum vancomycin concentration range and clinical efficacy (3-7). Likewise, there are few data to suggest that adverse effects are related to any particular serum concentration range (4-6). Indeed, whether vancomycin alone is nephrotoxic or ototoxic is controversial, although the balance of evidence does suggest that vancomycin potentiates aminoglycoside toxicity (7). Furthermore, standard vancomycin dosing with $2 \mathrm{~g} /$ day (either $1 \mathrm{~g}$ every $12 \mathrm{~h}$ or $500 \mathrm{mg}$ every $6 \mathrm{~h}$ ) in most adults with good renal function (or $30 \mathrm{mg} / \mathrm{kg} /$ day for children) consistently results in vancomycin peak concentrations from 18 to $47 \mu \mathrm{g} / \mathrm{mL}$ and trough concentrations from 2 to $13 \mu \mathrm{g} / \mathrm{mL}$. These concentrations are in excess of the minimum inhibitory concentrations for nearly all strains of $S$ aureus and Streptococcus species (9).

Finally, the cost and discomforts associated with serum vancomycin monitoring must be considered. Each pair of samples results in two additional venepunctures, and the cost of these two assays is approximately $\$ 38$ on a cost recovery basis (personal communication).

\section{RECOMMENDATIONS}

In view of the evidence, we and others (4-7) believe that routine monitoring of serum vancomycin concentrations is not indicated and should not be performed. However, there are a few select patient populations in which serum vancomycin monitoring should be considered. The first group of patients is those with rapidly changing renal function. The second is patients receiving hemodialysis with high flux dialysis membranes that are capable of removing some vancomycin (10). The third group of patients is those who appear not to respond clinically to vancomycin therapy. For other patients, periodic 
monitoring of serum creatinine is sufficient to detect when dose alterations should be made; these dose alterations can effectively be made by a dosing nomogram (11).

To conserve diminishing health care resources, the utility of all diagnostic tests must be critically evaluated. Tests that add costs without providing meaningful clinical benefits need to be abandoned. Routine serum monitoring for vancomycin concentrations clearly falls into this category of tests. Our precious health care resources can be far better utilized.

\section{REFERENCES}

1. Ena J, Dick RW, Jones RN, Wenzel RP. The epidemiology of intravenous vancomycin usage in a university hospital. A 10-year study. JAMA 1993;269:598-602.

2. Rybak MJ, Boike SC. Monitoring vancomycin therapy. Drug Intell Clin Pharm 1986;20:757-60.

3. Rodvold KA, Zokufa H, Rotschafer JC. Routine monitoring of serum vancomycin concentrations: can waiting be justified? Clin Pharm 1987;6:655-8.

4. Edwards DJ, Pancorbo S. Routine monitoring of serum vancomycin concentrations: waiting for proof of its value. Clin Pharm 1987;6:652-4.

5. Freeman CD, Quintiliani R, Nightingale $\mathrm{CH}$. Vancomycin therapeutic drug monitoring: is it necessary? Ann Pharmacother 1993;27:594-8.

6. Cantú TG, Yamanka-Yuen NA, Lietman PS. Serum vancomycin concentrations: reappraisal of their clinical value. Clin Infect Dis 1994;18:533-43.

7. Moellering RC Jr. Monitoring serum vancomycin levels: climbing the mountain because it is there? Clin Infect Dis 1994;18:544-6. (Edit)

8. Conly JM, Gold W, Shafran SD. Once-daily aminoglycoside dosing: a new look at an old drug. Can J Infect Dis 1994;5:905-6.

9. Cooper GL, Given DB. Vancomycin: A Comprehensive Review of 30 Years of Clinical Experience. New York: Park Row Publishers, Inc, 1986.

10. Quale JM, O'Halloran JJ, DeVincenzo N, Barth RH. Removal of vancomycin by high-flux hemodialysis membranes. Antimicrob Agents Chemother 1992;36:1424-6.

11. Moellering RC Jr, Krogstad DJ, Greenblatt DJ. Vancomycin therapy in patients with impaired renal function: a nomogram for dosage. Ann Intern Med 1981;94:343-6.

SD Shafran MD FRCPC Edmonton, Alberta JM Conly MD FRCPC Toronto, Ontario 


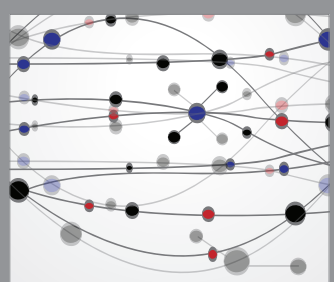

The Scientific World Journal
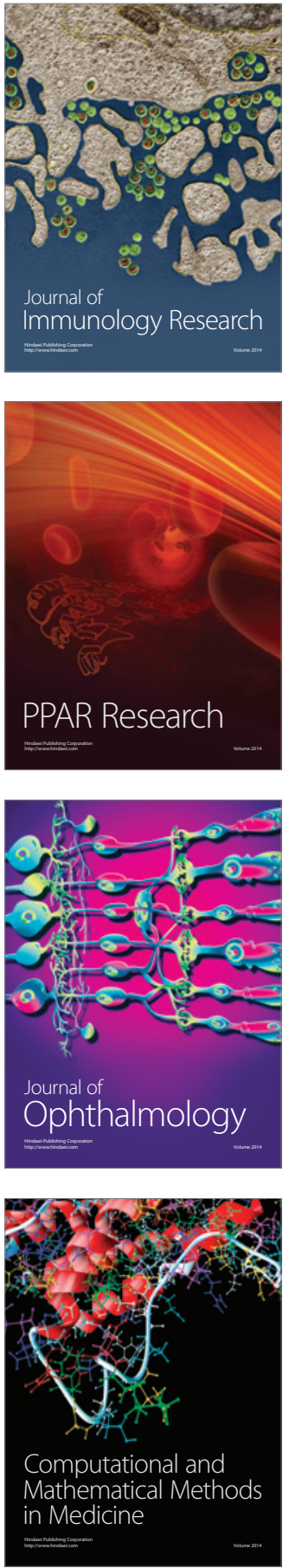

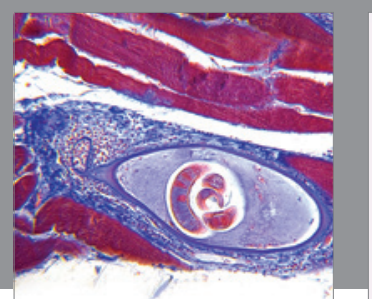

Gastroenterology Research and Practice

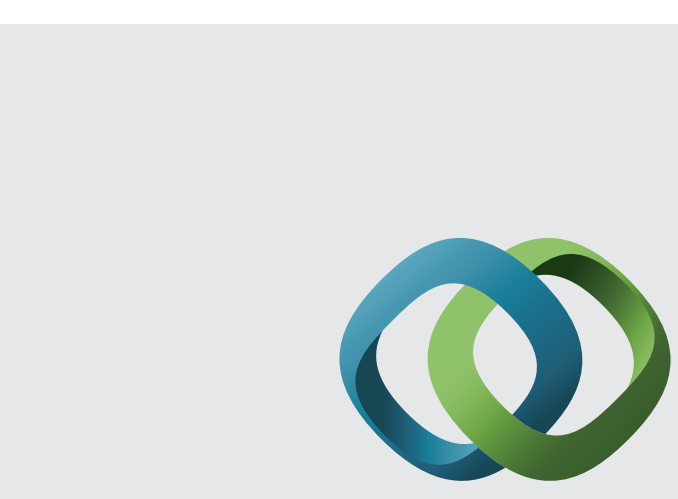

\section{Hindawi}

Submit your manuscripts at

http://www.hindawi.com
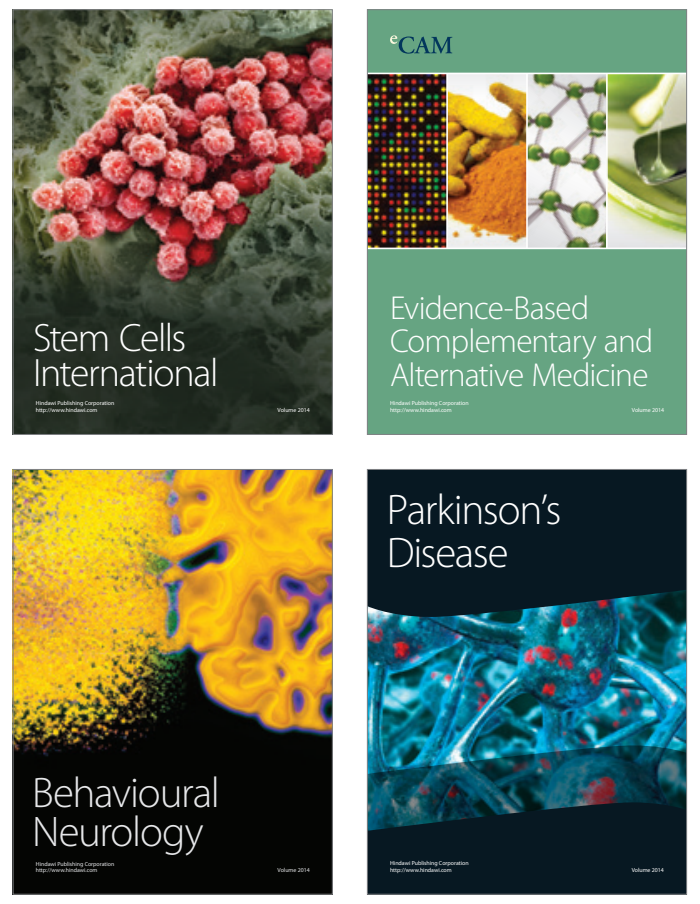
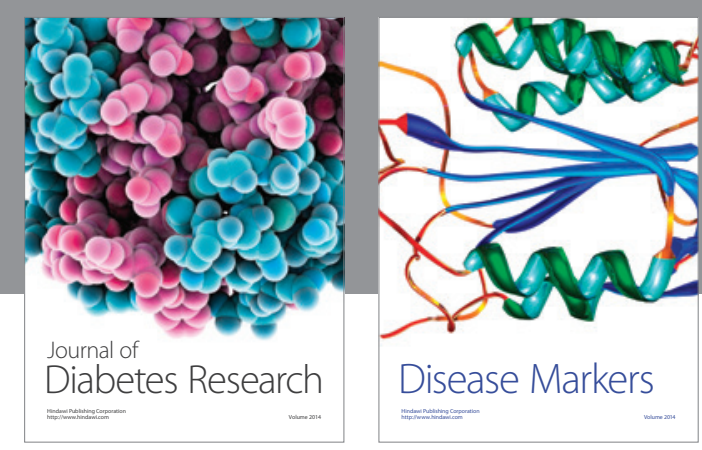

Disease Markers
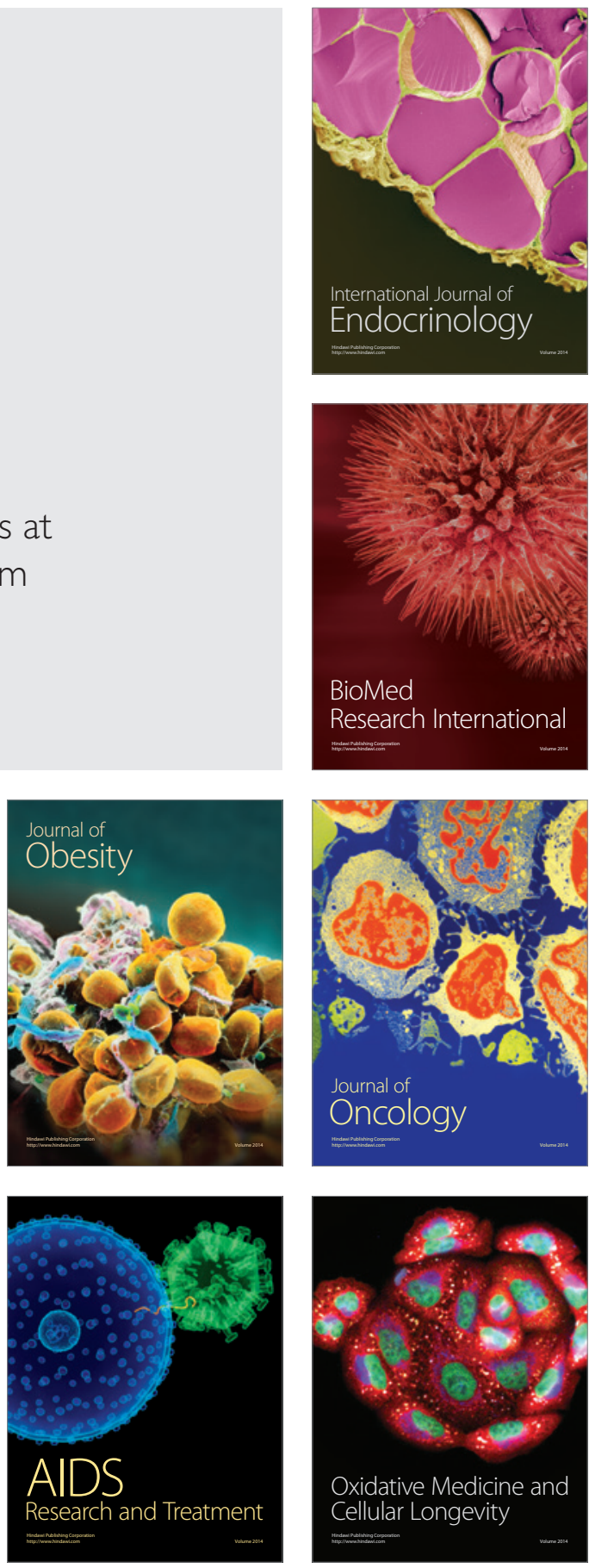